University of Nebraska - Lincoln

DigitalCommons@University of Nebraska - Lincoln

Publications, Agencies and Staff of the U.S.

Department of Commerce

U.S. Department of Commerce

2011

Age estimation and growth layer patterns in teeth of Commerson's dolphins (Cephalorhynchus c. commersonii) in subantarctic waters

\author{
Natalia A. Dellabianca \\ Centro Austral de Investigaciones Científicas (CADIC), ndellabianc@gmail.com \\ Aleta A. Hohn \\ NMFS-SEFSC-NOAA Beaufort Lab \\ R. Natalie P. Goodall \\ Centro Austral de Investigaciones Científicas (CADIC)
}

Follow this and additional works at: https://digitalcommons.unl.edu/usdeptcommercepub

Part of the Environmental Sciences Commons

Dellabianca, Natalia A.; Hohn, Aleta A.; and Goodall, R. Natalie P., "Age estimation and growth layer patterns in teeth of Commerson's dolphins (Cephalorhynchus c. commersonii) in subantarctic waters" (2011). Publications, Agencies and Staff of the U.S. Department of Commerce. 256.

https://digitalcommons.unl.edu/usdeptcommercepub/256

This Article is brought to you for free and open access by the U.S. Department of Commerce at DigitalCommons@University of Nebraska - Lincoln. It has been accepted for inclusion in Publications, Agencies and Staff of the U.S. Department of Commerce by an authorized administrator of DigitalCommons@University of Nebraska - Lincoln. 
MARINE MAMMAL SCIENCE, $* *(*): * * * \_* * *(* * * 2011)$

(C) 2011 by the Society for Marine Mammalogy

DOI: $10.1111 / \mathrm{j} .1748-7692.2011 .00475 . x$

\title{
Age estimation and growth layer patterns in teeth of Commerson's dolphins (Cephalorbynchus c. commersonii) in subantarctic waters
}

\author{
Natalia A. Dellabianca \\ Centro Austral de Investigaciones Científicas (CADIC), \\ Bernardo Houssay 200, \\ (9410) Ushuaia, Tierra del Fuego, Argentina \\ and
}

Museo Acatushún de Aves y Mamíferos Marinos Australes (AMMA), Sarmiento 44, (9410) Ushuaia, Tierra del Fuego, Argentina

E-mail: ndellabianc@gmail.com

Aleta A. HoHn

NMFS-SEFSC-NOAA Beaufort Lab, 101 Pivers Island Road,

Beaufort, North Carolina 28516-9722, U.S.A.

R. NATAlie P. GoOdall

Centro Austral de Investigaciones Científicas (CADIC), Bernardo Houssay 200,

(9410) Ushuaia, Tierra del Fuego, Argentina and

Museo Acatushún de Aves y Mamíferos Marinos Australes (AMMA), Sarmiento 44, (9410) Ushuaia, Tierra del Fuego, Argentina

The Commerson's dolphin, Cephalorbynchus c. commersonii, one of the world's smallest cetaceans, occurs in the southwestern South Atlantic from about $41^{\circ} 30^{\prime} \mathrm{S}$ to near Cape Horn $\left(56^{\circ} \mathrm{S}\right)$, including the central and eastern Strait of Magellan and the Falkland (Malvinas) Islands (Goodall 1978, Goodall et al. 1988). Along the coasts of Patagonia, northern Tierra del Fuego, Argentina, and the eastern Strait of Magellan, Chile, this is the cetacean most often seen near shore, where the animals feed and surf in the breakers. They seldom strand, but are commonly taken incidentally in shore-based gill nets set perpendicular to the coast over the wide tidal flats (Goodall 1978, 1994; Goodall et al. 1994, 2008; Iñíguez et al. 2003). Although there have been few aerial surveys, this is probably the most abundant small cetacean in these waters and is the most affected by bycatch in artisanal fisheries.

Age estimation in marine mammals by counting incremental layers in teeth has been carried out since the 1950s (Scheffer and Myrick 1980). As mentioned in Hohn (2002), the importance of age estimation goes beyond population dynamic studies, and the information on age at sexual maturation and population age structure may help to adopt adequate policies in conservation management (Read and Hohn 1995, Hohn et al. 1996). Additional information can be obtained from teeth, such as life history or environmental events (Klevezal and Myrick 1984, Manzanilla 1989; Lockyer 1993, 1995; Klevezal 1996, Luque et al. 2009). Therefore, the description 
of a "basic or typical" pattern of a species gives us not only more accurate and precise age estimates, but also allows for the identification of accessory layers (ALs) and other tooth-tissue alterations, which could be correlated with intrinsic or extrinsic factors.

Early studies of the teeth of Commerson's dolphins for ageing provided no detailed description of dentinal growth layer pattern (Lockyer et al. 1981, 1988; Pedraza 2008), although one of these studies (Lockyer et al. 1981) examined a small sample of teeth $(n=40)$. In our study we were able to significantly increase that sample size, allowing us to (1) define, identify, and characterize dentinal growth layer groups (GLGs, Perrin and Myrick 1980) using quantitative (relative size of growth layers) and qualitative (appearance of growth layers) features in good-quality sections; (2) describe the "basic" growth layer pattern and; (3) examine sexual dimorphism in GLG characteristics.

Teeth from 198 Commerson's dolphins from the R. Natalie P. Goodall (RNP) collection, held at the Museo Acatushún de Aves y Mamíferos Marinos Australes (AMMA) at Estancia Harberton, Tierra del Fuego, were available for this study. Specimens were collected during the RNP program of beach surveys along the coast of northern Tierra del Fuego from 1974 to present (Goodall 1978, Goodall et al. 1994). Data on collection date, stranding location, total length and sex were available for all specimens.

Initially, one tooth was selected from the center of the lower jaw or, if the teeth were no longer in the mandible, the straightest and least worn teeth were chosen. When the initial thin section was poor, another tooth was similarly selected and processed. Teeth were prepared following the method described in Myrick et al. (1983) and Hohn et al. (1989). They were placed in $10 \%$ formalin for up to $3 \mathrm{~h}$, rinsed well in water, and then decalcified in RDO. ${ }^{1}$ Decalcification time ranged from $40 \mathrm{~min}$ (in neonates) to $5.5 \mathrm{~h}$ (in older specimens). Decalcified and well-rinsed teeth were thin sectioned to $25 \mu \mathrm{m}$ on a freezing-stage microtome. For most specimens, tooth sections were obtained in a buccal-lingual (BL) orientation. In specimens with twisted teeth (usually older animals), the teeth were rotated, sometimes as much as $90^{\circ}$, to find an orientation that would allow for a mid-longitudinal section. Sections were stained in Mayer's hematoxylin and "blued" in a weak ammonia solution. The best sections were selected and mounted on a microscope slide in 100\% glycerin.

In Commerson's dolphins, cement is not well developed and its layers are inconspicuous (Lockyer et al. 1981), so only dentinal layers were counted in this study. Using a stereo microscope with transmitted light at $40 \times$ and $100 \times$ magnifications, the dentine of each specimen was read, without access to biological data, three times by NAD. Estimated age was taken as the last reading, under the assumption that the accuracy of counting increases with time (Pinedo and Hohn 2000). A subsample of teeth was read independently by $\mathrm{AAH}$ and the readings were compared. If different, a consensus was achieved. Additionally, consultation on growth-layer patterns continued between the authors during the readings in order to begin describing and defining the growth-layer pattern. We assumed, as in Lockyer et al. (1981, 1988), that in this species one GLG represents one year's growth.

\footnotetext{
${ }^{1}$ Reference to trade names does not imply endorsement by the authors' institutions.
} 


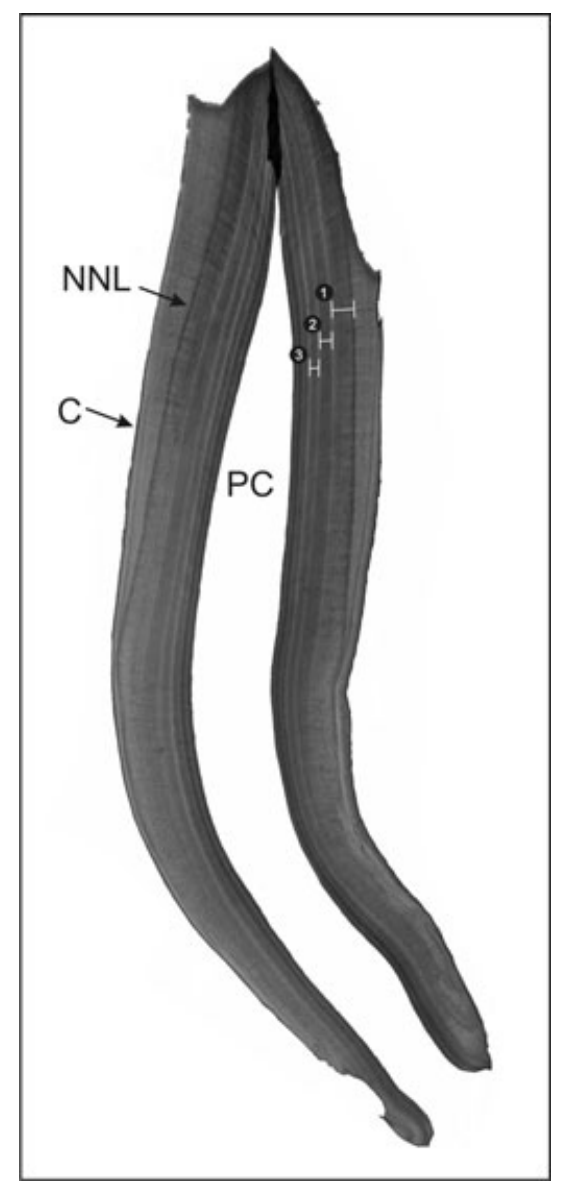

Figure 1. Location of GLG thickness measurements taken on a good quality (on-center) section of Commerson's dolphin C. commersonii tooth at $40 \times$ magnification. $\mathrm{NNL}=$ neonatal line, $\mathrm{C}=$ cement, $\mathrm{PC}=$ pulp cavity, numbers $=\mathrm{GLG}$ number.

In order to characterize the growth layer pattern, the GLG thickness was measured at specific locations on good quality BL sections (Fig. 1). Sections were considered as "good quality" following the criteria used by Hohn et al. (1989) and Pinedo and Hohn (2000). Due to the marked lateral asymmetry of Commerson's dolphins' teeth, measurements were always taken on the convex side. All measurements were obtained at $100 \times$ using Image-Pro Plus processing software.

We tested for sexual dimorphism in the mean GLG width using the Student's $t$-test at a $5 \%$ significance level. In addition, dentinal anomalies occurred in $50.5 \%$ $(n=100)$ of the specimens, usually within the four first GLGs. In those animals it was more challenging to delimit annual layers, so in order to help identify GLG boundary, the thickness of "typical" and anomalous GLGs were compared (Student's $t$-test at 0.05 ). In all cases the measurements compared were only from the first three 


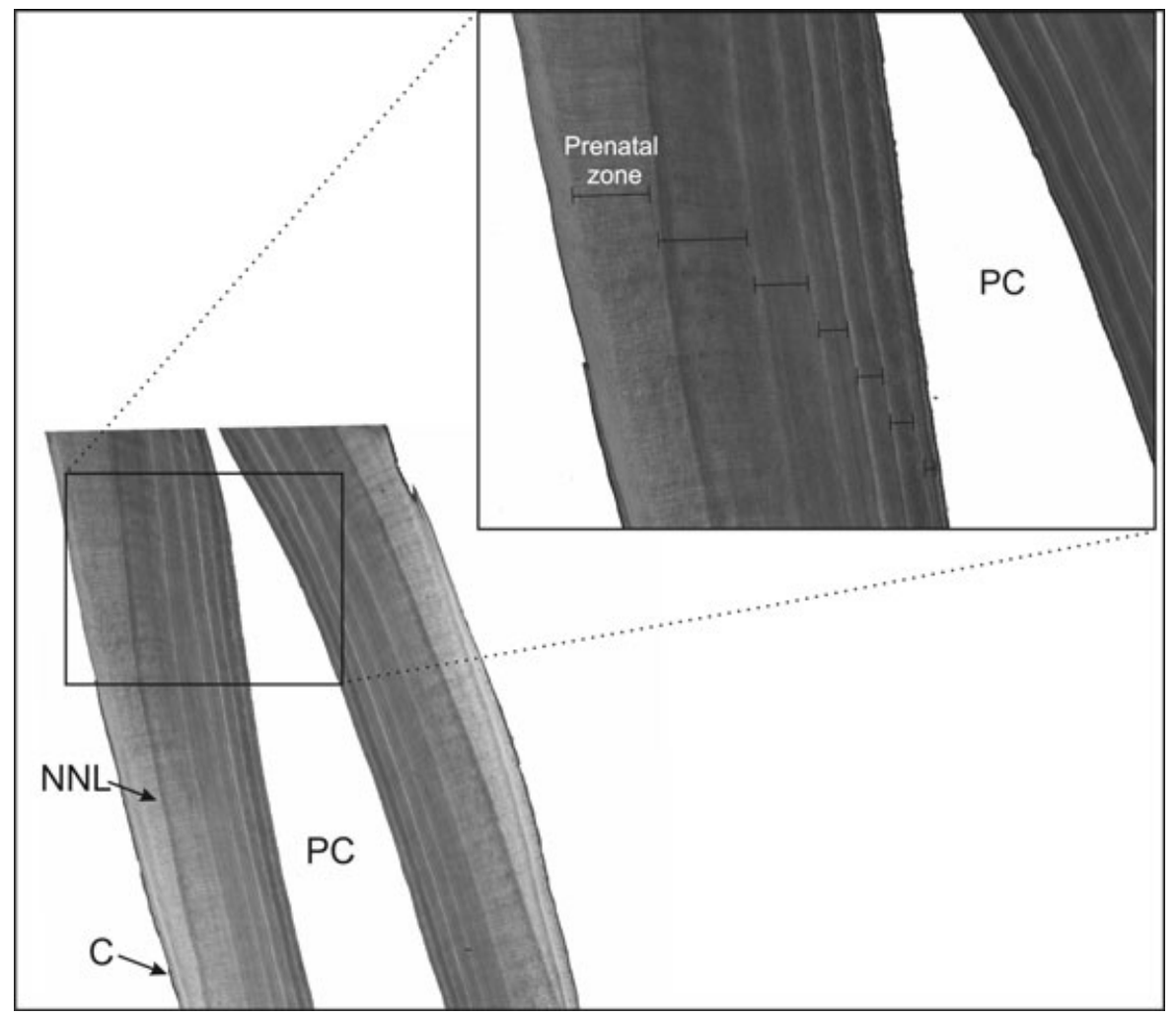

Figure 2. Dentinal growth-layer pattern in C. commersonii teeth. A 6 yr old male (RNP 1351 ) at $40 \times$ and $100 \times$ magnification (top right corner). $\mathrm{NNL}=$ neonatal line, $\mathrm{C}=$ cement, $\mathrm{PC}=$ pulp cavity.

GLGs, due to the small sample size of GLGs four and older for statistical analysis. We also examined the last layer deposited in order to determine the season of layer deposition for those specimens for which we had an exact date of death $(n=72)$.

As in other dolphin species, the dentinal GLG pattern in Commerson's dolphins consists of a thin, weakly stained layer (unstainable layer) and a thick stainable layer (Perrin and Myrick 1980, Hohn et al. 1989). The prenatal zone was homogeneous, without layering and considerably thinner than the first GLG at the base of crown in the convex side, where the cement layer begins. In contrast to what has been described for many species, appearance of the neonatal line was complicated. Rather than appearing primarily as a distinct, unstained layer, it consists of a very thin dark line adjacent to prenatal dentine, more evident at the apical zone, a narrow unstainable layer (the beginning of the first GLG) and an intensely stained broad layer. As previously described for other species (Myrick et al. 1983, Hohn et al. 1989, Pinedo and Hohn 2000), the boundary between two adjacent GLGs was delimited by a thin, dark stained layer, which was more conspicuous between GLGs 2-3 and subsequent GLGs than between GLGs 1-2 (Fig. 2). Moreover, the boundary between 
Table 1. Measurements ( $\mu \mathrm{m})$ of GLG thickness obtained for males $(\mathrm{M})$ and females $(\mathrm{F})$ of Commerson's dolphin. NS = not significant.

\begin{tabular}{lcrrccc}
\hline \hline GLG & Sex & Mean & \multicolumn{1}{c}{$n$} & \multicolumn{1}{c}{ SD } & Minimum/maximum & $t$-value $(P \leq 0.05)$ \\
\hline 1 & M & 237.19 & 27 & 25.12 & $173.11 / 283.29$ & NS \\
& F & 225.04 & 14 & 31.85 & $171.72 / 272.97$ & NS \\
2 & M & 131.79 & 22 & 24.83 & $94.03 / 176.73$ & \\
& F & 131.51 & 7 & 26.32 & $103.34 / 169.53$ & NS \\
3 & M & 79.32 & 16 & 13.35 & $58.41 / 97.35$ & \\
& F & 76.15 & 4 & 5.7 & $71.41 / 82.84$ & \\
\hline
\end{tabular}

the first and second GLGs was quite distinct in most specimens. The GLG pattern changed at the fifth or sixth GLG, at which time they became better defined with the unstainable becoming relatively wider and the stainable layer becoming relatively narrower, as described for bottlenose dolphins, Tursiops truncatus (Hohn 1980). When more than one tooth from a dolphin was used, the layering pattern was the same.

The relative thickness of the GLGs follows the same pattern found in bottlenose dolphins (Hohn et al. 1989), except that the second GLG is smaller than the first in Commerson's dolphins. No significant differences were found in the corresponding GLG width between male and female specimens (Table 1). Additionally, the mean width of anomalous and typical GLGs was not different in the first and second GLG, suggesting that thickness measurements may be a useful tool to identify these GLGs if the pattern is confusing. However, the thickness of the third GLG was significantly different (Table 2).

Most of the specimens analyzed showed a conspicuous pale AL in the first GLG, more evident in yearling specimens (Fig. 3). In addition, $22.6 \%$ of the specimens older than $5 \mathrm{yr}(n=115)$ had a thin dark layer in GLG 5, 6, or 7. Both of these features were considered ALs or marker lines and were not included in GLG counts. Anomalous dentinal GLGs were present in 100 specimens, mostly among the first four GLGs. They often presented two or three conspicuous wavy dark ALs and a relative "hypomineralized" appearance (Fig. 4). In 23 specimens ( $>7 \mathrm{yr}$ old) pulp stones were observed, which consisted of nodules with concentric rings, as described in Lockyer (1993) (Fig. 5).

Table 2. Measurements ( $\mu \mathrm{m}$ ) obtained for "typical" (T) and anomalous (A) GLGs, with results of significance test between GLG type. ${ }^{*}=$ significantly different at $P \leq 0.05$ and NS $=$ not significant.

\begin{tabular}{lcrrrcc}
\hline \hline GLG & GLG type & Mean & \multicolumn{1}{c}{$n$} & \multicolumn{1}{c}{ SD } & Minimum/maximum & $t$-value $(P \leq 0.05)$ \\
\hline 1 & $\mathrm{~T}$ & 231.56 & 22 & 33.15 & $171.72 / 283.29$ & $\mathrm{NS}$ \\
& $\mathrm{A}$ & 238.08 & 17 & 19.17 & $215.65 / 269.59$ & $\mathrm{~N}$ \\
2 & $\mathrm{~T}$ & 133.55 & 12 & 27.05 & $94.03 / 169.53$ & \\
& $\mathrm{~A}$ & 130.65 & 17 & 24.05 & $95.85 / 176.73$ & $2.95^{*}$ \\
3 & $\mathrm{~T}$ & 72.74 & 13 & 9.37 & $58.41 / 88.36$ & \\
& $\mathrm{~A}$ & 90.64 & 6 & 8.94 & $78.96 / 97.35$ & \\
\hline
\end{tabular}




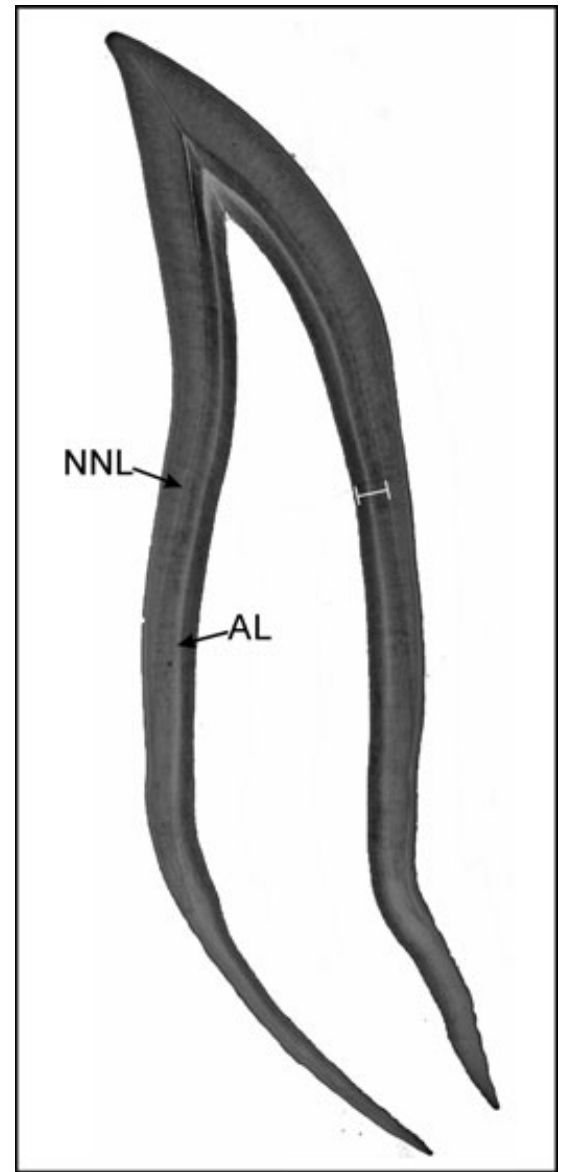

Figure 3. Prominent AL in dentine of a $1 \mathrm{yr}$ old female C. commersonii (RNP 1478). $\mathrm{NNL}=$ neonatal line.

In specimens stranded during summer the last layer deposited (adjacent to pulp cavity) was the unstainable one in $67.4 \%$ of the cases $(n=43)$, whereas in specimens stranded during autumn the last layer was stainable $(79.3 \%, n=29)$.

In our study, each GLG, which consisted of a thin unstainable layer and a thicker stainable layer, was considered as an annual layer when estimating age. Even though the Commerson's dolphins pattern should be validated with tetracycline or other marks to set a GLG as an annual pattern, its similarity to other delphinids growth patterns where GLGs were calibrated (i.e., bottlenose dolphins in Hohn et al. 1989) may allow this assumption. In addition, our results on the last layer deposited seem to support this assumption. Most animals, captured in the austral summer, showed the unstainable layer as the most recently formed. Births occur from November through March (Goodall et al. 1988). Assuming the neonatal line is deposited near the time of birth, a new annual GLG should begin to form at this time each year. 


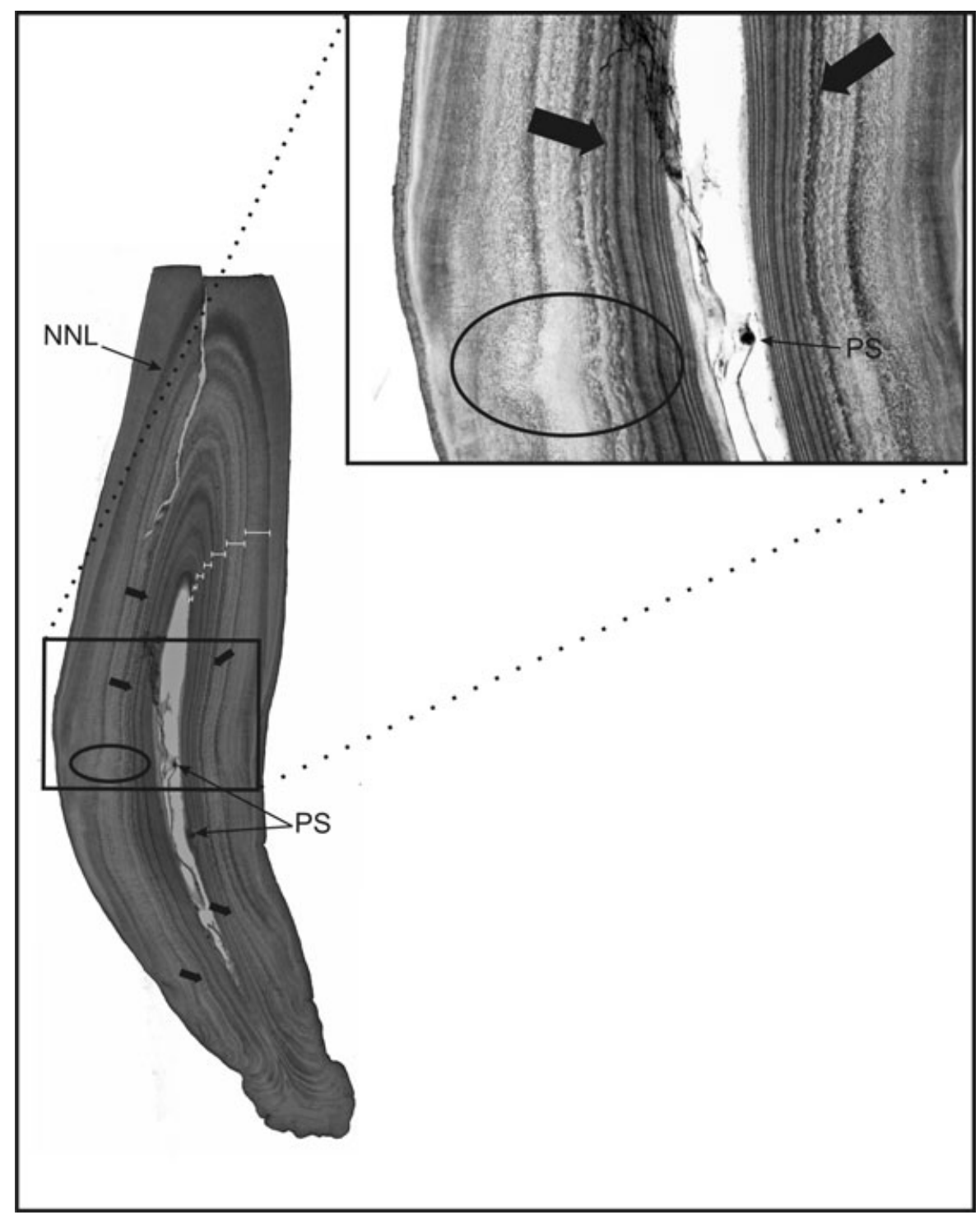

Figure 4. Wavy accessory layers (short arrows) and "hypomineralized" appearance (detailed in the circle) in an off-center section from a $7 \mathrm{yr}$ old male C. commersonii (RNP 620) at $40 \times$ and $60 \times$ magnification (top right corner). PS $=$ pulp stone, $\mathrm{NNL}=$ neonatal line.

Despite possible among-individual variation, layering was clear, GLGs distinct, and the ALs after the first GLG were not prominent in most specimens. Inconspicuous ALs make age estimation less problematic; reducing the probability of misinterpretation of the annual layering pattern (Hohn 1990). In addition, the boundary layer between the first and second GLG was conspicuous in most animals. This distinct 


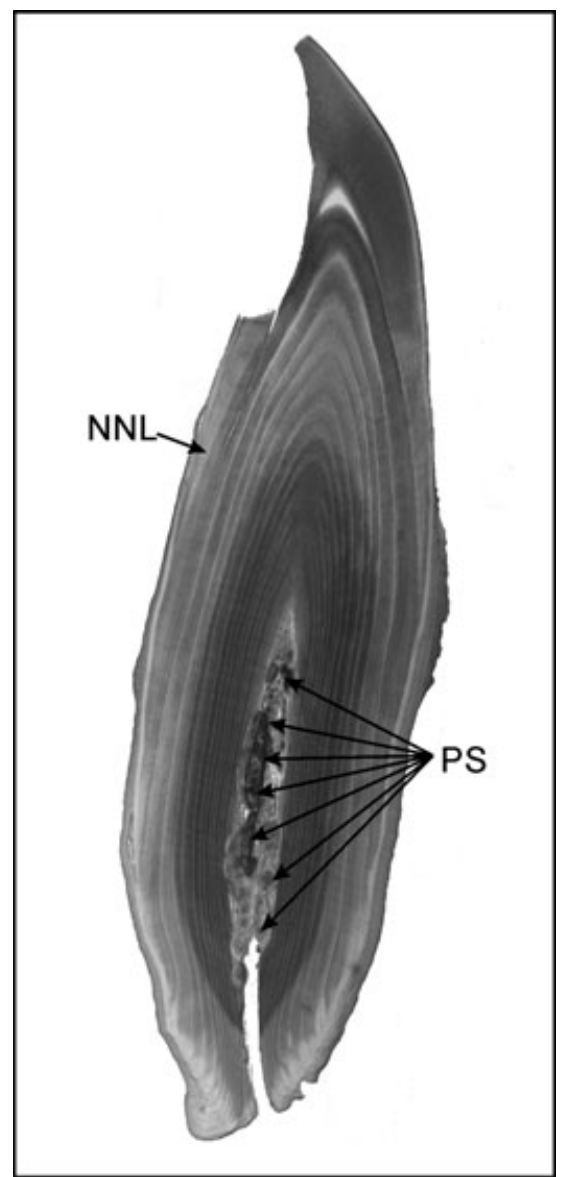

Figure 5. Many pulp stones (PS) in a $14 \mathrm{yr}$ old male $C$. commersonii $(\mathrm{RNP} 1073) . \mathrm{NNL}=$ neonatal line.

1-2 GLG boundary was observed in franciscana dolphins, Pontoporia blainvillei, and related to an early calcium intake by Pinedo and Hohn (2000). The same explanation might be applied here as well, since in Commerson's dolphins the nursing period also seems to be short. According to direct observation in captivity, calves stopped nursing before one year of age and ingested amounts of food similar to those of adults at age one (Joseph et al. 1987, Kastelein et al. 1993).

Usually, populations that have individuals with distinct growth layers inhabit areas with marked seasonal variability (Klevezal 1996). This could explain the distinctness of growth layers found in Commerson's dolphins' teeth from Tierra del Fuego. It might be informative to compare the GLGs of this population to those from other areas with less seasonal change, as well as to other odontocetes in southern Argentina or Chile. 
The relative width of the GLGs was consistent in all specimens indicating that this feature would be helpful to identify annual layer boundaries. However, the variability in absolute width, due to individual variation, orientation of the tooth when sectioned, or other factors, is too large to be reliable. In animals with an anomalous pattern, mean widths of the two first GLGs were similar to those of "typical" ones, reinforcing the utility of measurements. The differences observed in the third GLG could be an artifact of the small sample size, thus, a larger sample size may be necessary to elucidate it. The lack of detectable differences in the means and ranges of GLG width between males and females allows for pooling measurements for both sexes in future studies. However, given the small female sample size in this study, comparisons with a greater number of specimens are recommended.

The presence of a prominent AL midway between the neonatal line and the first GLG in most of the 198 animals sampled suggests this could be related to life events, possibly with the beginning of solid food intake. Joseph et al. (1987) found that a calf born in captivity began mouthing whole fish at approximately 2 mo of age and Kastelein et al. (1993) observed that the milk-dependent period continued for between two and eight months for six calves in captivity. The mark could also be due to a common environmental event or is regulated intrinsically since it is common in many delphinids.

Although the age at sexual maturation is not known for Commerson's dolphins, Lockyer et al. (1988) suggested it to be at about 5-6 yr. That age corresponds with the appearance of a thin dark AL in GLGs 5, 6, or 7 in 26 of 115 specimens sampled. A connection between ALs (as marker lines) and sexual maturation has been suggested in other cetaceans (Klevezal and Myrick 1984, Klevezal 1996). Additionally, at GLG 5 there is a transition in the pattern; GLGs become more distinct, suggesting a possibility that this represents the age of maturation, as has been suggested for other species (Klevezal 1996). Other tooth anomalies seem to be associated with particular years and environmental factors (Dellabianca et al., unpublished data), but this possible link needs further research.

The uniformity and consistency in GLG width and structure allow us to set guidelines that might be helpful to improve the precision of age estimation. Using these guidelines might be particularly important in this species because of the prominent AL found in approximately the middle of the first GLG in many of the animals. Counting this AL as a GLG would introduce a positive bias upward in age estimates, leading to underestimation of total length and age of sexual maturation (Hohn 1980, 1990). Given that Commerson's dolphins are, within the small cetaceans, the most affected by bycatch in artisanal fisheries in Tierra del Fuego and surrounding areas (Goodall et al. 1994, Iñíguez et al. 2003), knowing the age structure of bycaught specimens is necessary in order to implement adequate conservation policies.

\section{ACKNOWLEDGMENTS}

We thank Dr. D. Fernandez and the Laboratorio de Ecofisiologia of the Centro Austral de Investigaciones Científicas for facilitating access to optical equipment and $\mathrm{N}$. Easdale, M. Torres, and Dr. F. Santiago for their kind help with the editing of images. RNP is grateful 
to the Committee for Research and Exploration of the National Geographic Society and Total Austral S.A. for their continuing support. The efforts of many student interns and volunteers who searched beaches, cleaned specimens, and collected data over the last $35 \mathrm{yr}$, especially I. S. Cameron, A. R. Galeazzi, S. V. Macnie, C. C. Boy, and L. E. Pimper, are greatly appreciated. We thank the staff of the NMFS Protected Resources Branch in Beaufort, North Carolina, especially Shauna Ertolacci, for various assistance and support during the visit by NAD. This research was funded by the Marianne \& Benno Lüthi Foundation, Cetacean Society International, and Conservation, Research and Education Opportunities. NAD was also supported by a graduate fellowship from the Consejo Nacional de Investigaciones Científicas y Técnicas (CONICET) of Argentina.

\section{LITERATURE CiTED}

Goodall, R. N. P. 1978. Report on the small cetaceans stranded on the coasts of Tierra del Fuego. Scientific Reports of the Whales Research Institute, Tokyo 30:197-230.

Goodall, R. N. P. 1994. Commerson's dolphin, Cephalorhynchus commersonii (Lacépede 1804). Pages 241-267 in S. Ridgway and R. J. Harrison, eds. Handbook of marine mammals. Volume 5. The first book of dolphins. Academic Press, London, UK.

Goodall, R. N. P., A. R. Galeazzi, S. Leatherwood, K. W. Miller, I. S. Cameron and R. K. Kastelein. 1988. Studies of Commerson's dolphins, Cephalorhynchus commersonii, off Tierra del Fuego, 1976-1984, with a review of information on the species in the South Atlantic. Report of the International Whaling Commission (Special Issue 9):3-70.

Goodall, R. N. P., A. C. M. Schiavini and C. Fermani. 1994. Net fisheries and net mortality of small cetaceans off Tierra del Fuego, Argentina. Report of the International Whaling Commission (Special Issue 15):295-304.

Goodall, R. N. P., N. Dellabianca, C. C. Boy, L. G. Benegas, L. E. Pimper and L. Riccialdelli. 2008. Review of small cetaceans stranded or incidentally captured on the coasts of Tierra del Fuego, Argentina, over 33 years. Paper SC/60/SM21 presented at 60th Meeting of the Scientific Committee, International Whaling Commission, Santiago, Chile. 13 pp.

Hohn, A. A. 1980. Age determination and age related factors in the teeth of western North Atlantic bottlenose dolphins. Scientific Reports of the Whales Research Institute, Tokyo 32:39-66.

Hohn, A. A. 1990. Reading between the lines: An analysis of age estimation in dolphins. Pages 575-585 in S. Leatherwood and R. R. Reeves, eds. The bottlenose dolphin. Academic Press, New York, NY.

Hohn, A. A. 2002. Age estimation. Pages 6-13 in W. F. Perrin, B. Würsig and J. G. M. Thewissen, eds. Encyclopedia of marine mammals. Academic Press, San Diego, CA.

Hohn, A. A., M. D. Scott, R. S. Wells, J. C. Sweeney and A. B. Irvine. 1989. Growth layers in teeth from known-age, free-ranging bottlenose dolphins. Marine Mammal Science 5:315-342.

Hohn, A. A., A. J. Read, S. Fernández, O. Vidal and L. T. Findley. 1996. Life history of the vaquita, Phocoena sinus (Phocoenidae, Cetacea). Journal of Zoology, London 239:235251.

Iñíguez, M. A., M. Hevia, C. Gasparrou, A. L. Tomsin and E. R. Secchi. 2003. Preliminary estimate of incidental mortality of Commerson's dolphins (Cephalorbynchus commersonii) in an artisanal setnet fishery in La Angelina beach and Ría Gallegos, Santa Cruz, Argentina. Latin American Journal of Aquatic Mammals 2:87-94.

Joseph, B. E., J. E. Antrim and L. H. Cornell. 1987. Commerson's dolphin (Cephalorbynchus commersonii): A discussion of the first live birth within a marine zoological park. Zoo Biology 6:69-77.

Kastelein, R. A., J. McBain and B. Neurohr. 1993. Information on the biology of Commerson's dolphins (Cephalorbynchus commersonii). Aquatic Mammals 19:13-19.

Klevezal, G. A. 1996. Recording structures in mammals: Determination of age and reconstruction of life history. A. A. Balkema, Rotterdam, The Netherlands. 
Klevezal, G. A., and A. C. Myrick 1984. Marks in tooth dentine of female dolphins (Genus Stenella) as indicators of parturition. Journal of Mammalogy 65:103-110.

Lockyer, C. 1993. A report on patterns of deposition of dentine and cement in teeth of pilot whales, genus Globicephala. Report of the International Whaling Commission (Special Issue 14):137-161.

Lockyer, C. 1995. A review of factors involved in zonation in odontocete teeth, and an investigation of the likely effect of environmental factors and life history events on harbor porpoise tooth structure. Report of the International Whaling Commission (Special Issue 16):511-529.

Lockyer, C., G. G. Smellie, R. N. P. Goodall and I. S. Cameron. 1981. Examination of teeth of Commerson's dolphin, Cephalorbynchus commersonii, for age determination. Journal of the Zoological Society of London 195:123-131.

Lockyer, C., R. N. P. Goodall and A. R. Galeazzi. 1988. Age and body length characteristics of Cephalorbynchus commersonii from incidentally-caught specimens off Tierra del Fuego. Report of the International Whaling Commission (Special Issue 9):103-118.

Luque, P. L., G. J. Pierce, J. A. Learmonth, et al. 2009. Dentinal anomalies in teeth of harbor porpoises (Phocoena phocoena) from Scottish waters: Are they linked to sexual maturation and environmental events? Journal of the Marine Biological Association of the United Kingdom 89:893-902.

Manzanilla, S. R. 1989. The 1982-1983 El Niño event recorded in dentinal growth layers in teeth of Peruvian dusky dolphins (Lagenorbynchus obscurus). Canadian Journal of Zoology 67:2120-2125.

Myrick, A. C., A. A. Hohn, P. A. Sloan, M. Kimura and D. D. Stanley. 1983. Estimating the age of spotted and spinner dolphins (Stenella attenuata and Stenella longirostris) from teeth. National Oceanic Atmospheric Administration Technical Memorandum NMFS, SWFC-30. 17 pp.

Pedraza, S. N. 2008 Ecología poblacional de la tonina overa Cephalorbynchus commersonii (Lacépède, 1804) en el litoral patagónico. Ph.D. dissertation, Universidad de Buenos Aires, Buenos Aires, Argentina. 213 pp.

Perrin, W. F., and A. C. Myrick, eds. 1980. Age determination of toothed whales and sirenians. Report of the International Whaling Commission (Special Issue 3). 229 pp.

Pinedo, M. C., and A. A. Hohn. 2000. Growth layer patterns in teeth from the franciscana, Pontoporia blanvillei: Developing a model for precision in age estimation. Marine Mammal Science 16:1-27.

Read, A. J., and A. A. Hohn. 1995. Life in the fast lane: The life history of harbor porpoises from the Gulf of Maine. Marine Mammal Science 11:423-440.

Scheffer, V. B., and A. C. Myrick. 1980. A review of studies to 1970 of growth layers in the teeth of marine mammals. Report of the International Whaling Commission (Special Issue 3):51-63.

Received: 7 June 2010

Accepted: 11 February 2011 